\title{
Growing Up with Intimate Partner Violence at Home: Adolescents' Narratives on Their Coping Strategies
}

\author{
Jenniffer K. Miranda ${ }^{1}$ (1) $\cdot$ Natalia Olivares ${ }^{1} \cdot$ Marcelo A. Crockett $^{2,3}$ \\ Accepted: 26 November 2021 / Published online: 8 January 2022 \\ (c) The Author(s), under exclusive licence to Springer Science+Business Media, LLC, part of Springer Nature 2021
}

\begin{abstract}
Purpose The research on adolescents who have grown up around intimate partner violence (IPV) between their parents or caregivers has mostly focused on adolescent's victimization experiences and the negative impact of this type of violence on their mental health. More research is needed on how they respond to these experiences. The aim of this study is to understand adolescents' coping strategies regarding IPV between their parents or caregivers, from their perspectives.

Methods The participants were ten adolescents between 12 and 17 years old (4 female and 6 male), users of protection programs in Chile. Semi-structured interviews were conducted, using thematic narrative analysis afterward.

Results The results show seven coping strategies: intervention, social support seeking, protective role, positive resignification, hypervigilance, escape-avoidance, and denial. The narratives of the adolescents indicate that they face not only specific episodes of IPV but also the consequences and family dynamics that accompany this type of violence.

Conclusion Adolescents' coping strategies can be organized in a continuum of IPV integration-distancing, based on the degree and form of involvement in the experience. Growing up with IPV at home demands an early development of the sense of agency and taking a position in the face of violence, transitioning between active and victim roles.
\end{abstract}

Keywords Intimate Partner Violence $\cdot$ Narratives $\cdot$ Coping $\cdot$ Adolescents

Intimate partner violence (IPV) is a global problem that not only affects women, but also their children, who become involved in this type of violence in various ways (Evans et al., 2008; Heise and García-Moreno, 2002; Holt et al., 2008). In Latin America, the widespread phenomenon of violence in general (Imbusch et al., 2011) and violence against children and adolescents -perpetrated by caregivers and peers, in particular- (Devries et al., 2019) is

Jenniffer K. Miranda

jmimirand@uchile.cl

Natalia Olivares

olivareso.natalia@gmail.com

Marcelo A. Crockett

mcrockett@ug.uchile.cl

1 Departamento de Psicología, Facultad de Ciencias Sociales, Universidad de Chile, Avenida Capitán Ignacio Carrera Pinto 1045 Ñuñoa, Santiago, Chile

2 Millennium Nucleus To Improve the Mental Health of Adolescents and Youths (Imhay), Santiago, Chile

3 Escuela de Salud Pública, Facultad de Medicina, Universidad de Chile, Santiago, Chile well-documented. In Chile, data on the co-occurrence of different forms of victimization during adolescence shows that $37 \%$ have had four or more different victimizations during the last 12 months (Pinto-Cortez et al., 2018). Specific data on IPV show that $12.8 \%$ of adolescents between 7 and 11 th grade report having witnessed physical IPV between their parents (Consejo Nacional de la Infancia, 2018). In contrast, in another study, $29.8 \%$ of children and adolescents between 6 and 12th grade reported IPV between their parents, with psychological violence being the most frequent occurrence (Subsecretaría de Prevención del Delito, 2013).

After three decades of research, it is well-established that IPV has a significant negative impact on the development and well-being of children and adolescents (Artz et al., 2014; Evans et al., 2008; Kitzmann et al., 2003; Vu et al., 2016; Wolfe et al., 2003). Adolescents also present high levels of aggression in relationships with peers and, in some cases, with their own partners and parents (Howell et al., 2016; Izaguirre \& Calvete, 2015), together with antisocial behaviors and the commission of violent crimes in young adulthood (Howell et al., 2016). Despite the deleterious impacts related with IPV, quantitative studies have shed little light 
onto youths' own understanding of the violence ( Akerlund \& Sandberg, 2017; Noble-Carr et al., 2020; Ravi \& Casolaro, 2018), suggesting that more studies are needed to explore how they cope with IPV (Hines, 2015; Ravi \& Casolaro, 2018).

\section{Coping and Adolescents in IPV Contexts}

By developing a process-oriented approach to coping in their seminal work, Richard Lazarus and Susan Folkman (1984) defined coping identifying four key points: “(1) constantly changing cognitive and behavioral (2) efforts to (3) manage specific external and/or internal demands (4) that are appraised as taxing or exceeding the resources of the person" (p.141). This widely-known definition of coping is especially useful to research that includes the perspectives of youths growing in IPV contexts, since, according to their authors, it allows: (1) a process-oriented approach; (2) avoiding conflating coping with outcome; (3) avoiding equating coping with mastery; and (4) a distinction between coping and automated adaptative behavior. Coping strategies can be grouped into two main categories, proposed as functions: a) problem-focused, directed at managing or altering the problem causing the distress; and b) emotion-focused, directed at regulating emotional response to the problem (Lazarus, 1999; Lazarus \& Folkman, 1984). It regards coping as the effort to manage stressful demands, independently of the outcome; therefore, no strategy is considered inherently better than any other. Consequently, to understand and evaluate coping, we need to know what the person is coping with (Lazarus, 2006; Lazarus \& Folkman, 1984). Some of these elements have contributed to the current comprehensive research on youth coping with IPV (Hines, 2015; Ravi \& Casolaro, 2018), highlighting those advocating that the adaptiveness/effectiveness of a coping strategy should be evaluated contextually: IPV faced by a particular youth, in a particular context (Miranda et al., 2021c; Øverlien and Hydén, 2009).

Coping plays a key role in adapting to the multiple stressors frequently experienced by adolescents who have grown up with IPV (Goldblatt, 2003; Hines, 2015). In the context of IPV, coping strategies are the ideas, interactions, and behaviors that adolescents use to deal with the experience and to understand this form of violence (Goldblatt, 2003). Some authors have conceptualized coping strategies in the context of IPV within a continuum that ranges from the integration of to the distancing from violence (Ravi \& Casolaro, 2018). This concurs with the general idea of coping as a process formulated by Lazarus and Folkman (1984) and their coping categories: problem-focused and emotion-focused. Thus, in Ravi and Casolaro's (2018) classification of coping strategies to face IPV, at one end of the continuum they include coping strategies that integrate violence in their attitudes and actions -physically or mentally- through its normalization or minimization, and/or through its incorporation into their daily activities, in a healthy or unhealthy manner. At the other end of the continuum, there are coping strategies that seek to distance themselves, consciously or subconsciously, from the experience of violence, either mentally or physically. This end of the continuum may include escape, avoidance and denial strategies that seek to elude IPV episodes or their consequences.

Previous research has documented that adolescents who have grown up in homes with IPV use various coping strategies to deal with violence, such as direct interventions to stop it, seeking social support, company or help, calling the police, leaving the vicinity, distancing themselves mentally by reading, listening to music, playing sports or sleeping (Aymer, 2008; Chanmugam, 2015; Hines, 2015; Øverlien \& Hydén, 2009; Ravi \& Casolaro, 2018), and by developing and using security plans, fantasy or religion (Aymer, 2008; Hines, 2015). A comprehensive understanding of adolescent's coping strategies often implies reconceptualizing some behaviors that can be considered maladaptive (Aymer, 2008; Chanmugam, 2015), considering that coping strategies in IPV contexts represent efforts to adapt to a maladaptive situation. It has been suggested that adolescents' coping strategies are used to survive in a violent environment and could become a positive outcome despite the context, since these experiences can provide flexibility and versatility to face other types of complex situations (Goldblatt, 2003).

Both quantitative and qualitative research on adolescents' coping strategies has predominantly been based on reports through questionnaires and have relied on mothers as informants (DeBoard-Lucas \& Grych, 2011; Goldblatt, 2003; Kimball, 2016; Kitzmann et al., 2003). Most of these studies have been carried out in contexts other than Latin America (Åkerlund \& Sandberg, 2017; Aymer, 2008; Benavides, 2012; Goldblatt, 2003; Hague et al., 2002; Hines, 2015; Katz, 2016; Øverlien \& Hydén, 2009). Previous research has emphasized that is important to include adolescents' perspectives about their own experiences of violence at home (Goldblatt, 2003) to achieve a better understanding of the phenomenon. Several studies have focused mainly on the negative outcomes on children's and adolescents' mental health and development, building a vision of them as passive victims, inevitably and irreparably damaged (Callaghan et al., 2015). Specifically, research that includes adolescents tends to show them as a reflection of harmful experiences lived in childhood, but they do not examine the meanings or responses to such experiences (Goldblatt, 2003). Consequently, there are gaps in the literature that limit the understanding of the nuances and complexities of adolescents' experiences and the ways in which they cope (Goldblatt, 2003; Kimball, 2016; Noble-Carr et al., 2020). 
Considering all the above, the aim of this study is to understand adolescents' coping strategies regarding IPV between their parents or caregivers, from their own perspectives. This work adds to the efforts to extend the scant knowledge that currently exists, particularly on children and adolescents that have grown up with IPV in Chile and Latin America (Miranda \& Corovic, 2019; Miranda et al., 2021b, c, d).

\section{Methods}

This study is part of a pioneering research project in Chile and Latin America that focuses on addressing the experiences of children and adolescents who have grown up in homes with IPV, from their own perspectives (more details in Miranda et al., 2021c).

\section{Participants}

The present study included ten adolescents (four female and six male) between 12 and 17 years old, users of programs for victims of maltreatment in Chile. According to the mothers' report, all the adolescents audibly experienced episodes of the IPV and seven of them also did so visually. Nine participants have also suffered other victimizations. The ten participants have siblings and the perpetrator of violence is their biological father for all cases bar one, where the perpetrator is the stepfather. In all cases but one, the parents were separated (in terms of marital status) at the time of the interview. The characteristics of the participants are presented in Table 1.

The inclusion criteria were: (a) aged between 12 and 17 years old, b) having lived experiences of IPV (psychological, physical, and/or sexual) during the last year, (c) children having a court referral certificate stipulating "Witness of Domestic Violence" or having a documented history of living with IPV, depending on the program that he or she is attending, (d) currently living with their mothers and having lived with her for at least 6 months during the previous year, and (e) undergoing diagnostic assessment in the program. This was in order to avoid a re-victimization of the participants (Eriksson \& Näsman, 2012) and contribute to the psychotherapeutic process. To protect the well-being of the participants, the following exclusion criteria were established: (a) children and mothers with a protected name and/or address, and (b) cases with a court order indicating that children are currently living in a situation assessed as high risk.

\section{Production Techniques and Data Collection}

A semi-structured interview was used for children and adolescents who have grown up with IPV (Callaghan et al.,
2015), using the version adapted by the project led by the first author (see script in: Miranda et al., 2021d). Semi-structured interviews were used to access the subjective experiences of the adolescents, because the format allows open and frank responses by the interviewees (Gaínza, 2006). This interview has allowed us to adequately explore the three thematic axes addressed by this research: experiences of IPV in children and adolescents, its impact and coping strategies (Miranda et al., 2021b, c, d). This study used the results of adolescent coping strategies.

\section{Ethical Considerations}

All the procedures in this research project were approved by the Ethics Committee of our institution. Following international recommendations on the protection of participants (Eriksson \& Näsman, 2012; Morris et al., 2012), the following measures were taken: 1 ) the program professionals were trained by the research team in the investigation protocol, 2) an Evaluation and Containment Protocol was drawn up in case the participants presented an emotional affectation or disclosed other experiences of violence or risk, 3) for the selection of cases, a risk assessment was carried out between members of the research team and the program professionals with the aim of ensuring that children and adolescents in situations of high risk of possible harm did not participate in the study (Morris et al., 2012), 4) to participate in the study, assent was requested from the adolescents together with the informed consent of their mothers, and 5) the names of the participants were changed to protect their anonymity.

\section{Procedure}

As with previous studies (Miranda et al., 2021b, c, d), this research was conducted following the below procedures: (1) The research team established contact with Program Directors and their therapists, and specialized training on IPV was given by the research team. The purpose of this training was: a) to present, analyze and reflect on recent knowledge in the IPV field, and b) to inform the participating professionals of the characteristics of this study, the instruments and procedures to be implemented; and, especially, to advise on the ethical aspects related to these. (2) The therapists referred to the research team any cases that met the selection criteria and, together, the risk of participation was evaluated for each case. (3) Once the case was selected, the therapists told the mothers about the research; when they expressed their interest in participating, a member of the team reached to inform them of the project, ask about their desire to participate, answer their concerns and ask them to consult with their children about their wish to participate. (4) When both (mother and adolescent) agreed to participate, the research team first asked separately for informed consent from the 


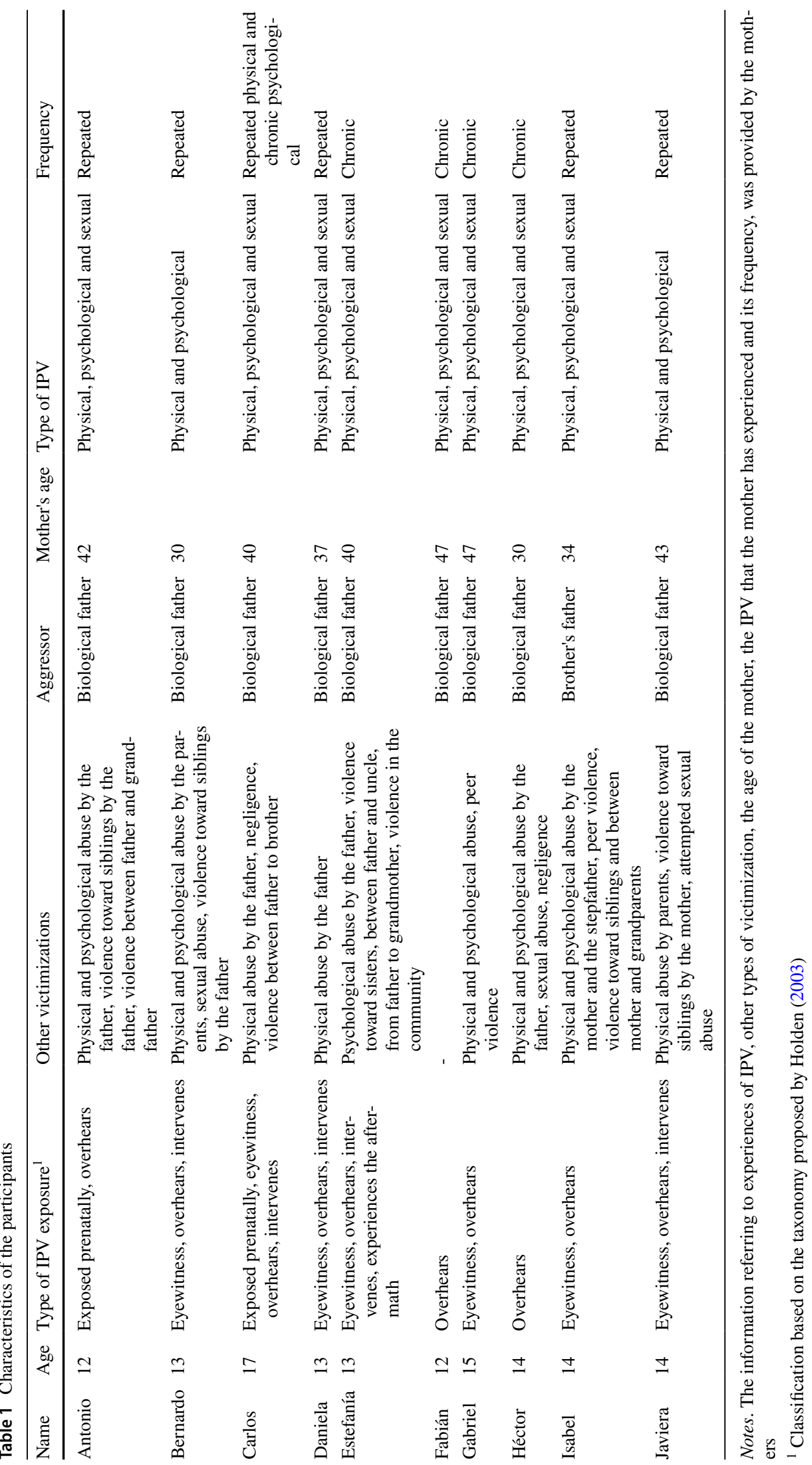


mother and then for informed assent from the adolescent. (5) With the informed consents and assents from both (mother and child), the therapists/professionals conducted the corresponding interviews. These were audio recorded and then transcribed.

\section{Data Analysis}

Thematic narrative analysis was used, which allows the systematic study of personal experience and meaning, i.e., how events have been constructed and ordered by people to give meaning to the events and actions in their lives (Riessman, 2002). This study uses the same analysis strategy described in previous research under the major pioneering project mentioned (see Miranda et al., 2021b, c, d), following the recommendation in qualitative research to address the issues of credibility, transferability, dependability, and confirmability (Korstjens \& Moser, 2018; Morse et al., 2002). The interview transcripts were analyzed by members of the research team. Then, the following steps were taken: 1) Intra-case analysis was conducted by each member of the research, coding and condensing each adolescent's interview. Joint coding sessions were held between team members, implementing analyst triangulation and carrying out an intra-case analysis. 2) Inter-case analysis was carried out to visualize differences and similarities, discussing and organizing themes and subthemes. It is important to note that the analysis performed by the authors was later discussed with all members of our research team, reinforcing the rigor and quality of the process through triangulation. Thus, data were systematically checked, information was triangulated, and the data fit and conceptual work of analysis and interpretation was monitored (Morse et al., 2002). The ATLAS.ti software (version 7.5.4) was used for the coding of the interviews. This study used the saturation criterion proposed by Morse et al. (2002), which is reached when there is enough richness in the testimonies of adolescents to comprise novel information on the subject.

\section{Results}

The analysis of the adolescents' narratives allowed the identification of seven main themes: 1) intervention, 2) social support seeking, 3) protective role, 4) positive resignification, 5) hypervigilance, 6) escape-avoidance and 7) denial, which were organized on a continuum from integration to distancing, as proposed by Ravi and Casolaro (2018). In general, adolescents were characterized by using multiple strategies to face IPV and to face other victimizations they have suffered. Verbatim quotes of the participants (here translated into English) are included within each theme.

\section{Intervention}

This coping strategy reflects the adolescents' verbal and physical actions to stop the violence between their parents. This type of strategy was used by half of the participants: two males (13 and 17 years old) and three females (13 and 14 years old). Some of them declare that, in their past, they used other strategies (e.g. escape or avoidance) but currently use intervention, reflecting a change in the way they face IPV situations as they grow older.

The narratives of these five adolescents reflect that most of them act during the occurrence of the aggressions and that they act after the IPV episodes to a lesser extent. Four participants intervene verbally and two physically. Regarding verbal intervention, three of them use it during the episode in a mediating role, trying to calm the situation down by asking their parents to stop or expressing that violence is not the way to solve problems.

Yes, because when my mother fought with my father, I told them to stop, because it was too much already...

(Javiera, 14 years old)

Two adolescents report that, after the episodes, they give advice to their parents, on one hand beseeching their mother to separate and, on the other, beseeching their father to change.

So I always told my mom: get away from him ... because if you keep holding the rope taut you'll both break your wrists, but if you let go you'll be ok... So,

I told them to live their own lives ... but they ignored me and continued to stay, until they began to do more damage. (Javiera, 14 years old)

One of the adolescents who intervenes in a physical way uses her body to try to separate her parents during the fight, while the other participant was the only one who reports having hit his father in order to defend his mother. Both point out that, with these actions, they managed to end the IPV episode. The narratives show that the participants feel that direct and physical actions are more effective in the immediate and long-term cessation of violence than interventions that are only verbal.

Hmm I almost hit my dad once, when he was arguing with my mom. (And did you do it or did the situation stop before that?) [...] I pushed him against the wall ... And then he stopped. (Bernardo, 13 years old)

The case of the oldest of the participants stands out. In addition to kicking the father out of the house and mediating when he tried to return, he was the only participant who initiated a judicial process for the violence exercised against the mother. 
Yes, I mean, when I filed the complaint and started the whole process, I had decided on what I wanted to do and how far I wanted to go. (Carlos, 17 years old)

A lack of intervention was observed in the narratives of two adolescent females, motivated by either fear or hopelessness because they consider that there is no possibility of change in the dynamics of IPV.

(Do you feel that someone can do something?) No, because if my nana [reference to maternal grandmother] couldn't... I don't think there is someone. (Isabel, 14 years old)

\section{Social Support Seeking}

This category reflects the actions implemented by the adolescents to seek help or support from persons that they trust. All the participants go to a significant person to talk about the experiences of IPV between their parents. Most participants resort to adults, such as grandparents, aunts or godparents, with the conviction of finding in them empathy, emotional support and also assistance in stopping the violence-and, therefore, protection.

I think calling my godparents could still make me feel better because... it would help to separate them.

[Referring to parents during an episode of IPV] (Daniela, 13 years old)

Four participants also talk to peers about IPV, such as their partner, friends and siblings. Adolescents go to people who have gone through situations similar to theirs and/ or with whom the level of trust is very high, seeking support and emotional containment. Three of the six adolescent males mentioned going to their friends, mainly during the IPV episode, to receive emotional support and distract each other from what is happening at home.

Yes, because... like, with friends you can, like, er... talk or also they can support you and also sometimes...

they... I don't know, like... er, we joke around, and I

forget things. (Héctor, 14 years old)

The narratives of three participants display their desire to potentially seek professional support for the parental figures. Adolescents attribute responsibility for situations of IPV to the father and, to a lesser extent, to the mothers, so they consider that they require professional help. For the adolescents, the emerging solutions to the problem are psychologists for their parents and/or drug rehabilitation spaces for the father figure.

I think everything would have been different if my dad had gotten into that, into... (Rehabilitation?) rehabilitation... Because it would be very different now...
Maybe my mom would be with him and it would be better. (Estefanía, 13 years old)

\section{Protective Role}

This strategy refers to the role that the adolescents took in relation to the needs of other persons at home to protect them from violence, specifically in situations where the parents did not fulfill their roles. Four participants -three males and one female- express that IPV experiences are strongly linked to a lack of protection and minimal care, both while their parents were together as well as after their separation. In these cases, they report a lack of parental competencies on the part of the father, whom they describe as having alcohol consumption issues or as an absent figure. Regarding the mother, the adolescents point out that they are not physically or emotionally available. Most narratives tell of an association between being an older sibling and having an active and protective role, and whose function is to defend and protect the victim, be it a younger sibling or the mother.

Because I'm the oldest, I defend my mom. (Bernardo, 13 years old).

Because my sister (reference to older sister, 17 years old) always defended my mother when my dad hit her

... because she preferred my dad to hit her rather than

my mother. (Estefanía, 13 years old)

As a way of dealing with violence, the four participants describe a relationship of care among siblings that implies that the oldest adopt(s) a protective role and the youngest the role of the protected. Thus, older siblings -mainly males-, become the figures in charge of the care of their younger siblings, going on to embody the paternal role in most family dynamics. This entails -as a subjective experience for the older sibling(s)- the feeling that their own needs are not being met and that assuming the responsibilities of taking care and protecting their sibling was not normal for their age. Only one adolescent indicated that the relationship of care that exists with his siblings seems positive to him, since his little brother listens to and obeys him.

Well, Simon is little [12 years old] uh, you can understand that he's a little boy, that's why he's a little messy, but...hmmm I mean, at home, for example, in the relationship we have with our brother, Simón behaves well and everything. Like, he does pay attention to us [reference to older siblings]. (Gabriel, 15 years old)

I always liked having responsibilities, but it's not, now that I see it, it's not something that I should have done, or that was my responsibility, but I did it because... In the end it was what I had to do to keep my brother ok. (Carlos, 17 years old) 


\section{Positive Resignification}

This strategy refers to the adolescents' ability to reflect on IPV, which consists of analyzing the experience and transforming it into a positive element in their lives. In these adolescents, their cognitive responses and the meanings associated with IPV allow them to counteract the harmful effects that this type of violence entails. The narratives of these participants also stand out for including longer and more detailed responses about their experiences of IPV at home.

Age seems to be relevant in this coping strategy, as it is observed in older adolescents -15 and 17 years old- who transform IPV into a tool and an opportunity for learning, change and personal growth. We can observe, for example, the development of a positive attitude toward the future, both personal and familywise.

Uh try to find the best way, try to take refuge in whatnot in the bad, in the good, so I can-because if you take refuge in the bad, unfortunately you start to think, to think, and think, and you think a lot and that's bad for you and I prefer, for example, to try to put them aside and solve it than to have it there, to try to solve it but always have it there. (Gabriel, 15 years old) I mean, it's difficult to grow up in that environment, but I believe that everything always leaves a-a learning that you have to look at positively. And if I see that my mother was disrespected and I saw that within my family there was disrespected, I know that shouldn't happen again, in the next family that I would like to form in the future or the one that my brother might want to form. (Carlos, 17 years old)

It should be noted that half of the adolescents explicitly express their intention not to repeat the patterns and dynamics of violence in the future. They emphasize the construction of relationships based on communication, respect, and a dialogue free of violence as an element that could make it possible to change the dynamics of IPV. This shows a deliberate assessment of their own experience, from which they determine possible solutions to avoid experiencing violence in the future. This may reflect an incipient positive resignification of their experience.

(What do you think other people can do to change this situation?) I think ... what is it called? That they should talk about it [...] and look for a solution for it to end. (Daniela, 13 years old)

\section{Hypervigilance}

Hypervigilance is another way to deal with IPV and other forms of violence that coexist within the family, such as episodes of abuse toward the children by the mother. This coping strategy consists of maintaining a constant state of alert to the possible occurrence of new episodes of violence and/or more serious events, as was reported by two adolescent females. The narratives reflect that this state of hypervigilance is aimed at protecting themselves, their mothers, and siblings, since the aggressor's reactions were unpredictable and caused great fear. This strategy is understood as a manifestation of the efforts made by the adolescents to achieve a sense of greater internal and external control. These efforts translate into the adolescents regulating their behavior to prevent future episodes of violence, consequently restricting their freedom of action because the adolescents understand that, when confronting a violent episode, they also risk being the recipients of violence.

$$
\begin{aligned}
& \text { [...] every child would not like to live what we live } \\
& \text { through... because... to see how your mom gets hit } \\
& \text { sucks ... because you, wanting to help her, you can't ... } \\
& \text { knowing that you can get hit. Because if we [referring } \\
& \text { to herself and her sisters] got involved, he might also } \\
& \text { hit us [...]. (Estefanía, } 13 \text { years old) } \\
& \text { It affects me, but I can't do anything (Why do you feel } \\
& \text { like you can't do anything?) Because I can't tell him } \\
& \text { not to hit them or not to do that because, in the end, he } \\
& \text { ends up doing those things to me. (Isabel, } 14 \text { years old) }
\end{aligned}
$$

\section{Escape-Avoidance}

This type of coping strategy represents the distancing mechanisms exhibited by seven participants of both genders when faced with IPV. It consists of physical behaviors of escaping/leaving the place where the violence is occurring and/ or mentally distancing from a specific episode of violence between their parents. Avoidance refers to behaviors that make it possible to emotionally and cognitively inhibit the discomfort associated with IPV. These behaviors serve as relaxation and distraction from the thoughts associated with the violent situations occurring between their caregivers and the negative emotions caused by them. About half of the adolescents employ this strategy through music, whether listening to it, playing it and/or singing. Other actions that appear in their narratives to a lesser extent are games, watching movies, letting go of the situation and thinking of pleasant and happy things.

Later, when I could have headphones, I would listen to music, and then as a last resort I would shut myself [in my room] and sing and try to forget what they were doing, that they were fighting. (Carlos, 17 years old) No, what I like to do when I am angry or when they are fighting is to go upstairs and start doing, like, watch movies ... Because, like, I distract my mind and I don't 
think about it and I ... I get into the movie. (Javiera, 14 years old)

Six participants, in addition to avoidance, describe escape behaviors. These imply flight from where the violence occurs, such as locking themselves in their rooms or bathrooms, going out to the back yard, going out for a walk or going out to play ball, which allows adolescents not to witness the episodes of IPV and thus avoid their consequences.

Uh I don't know. I'd try to ignore it, I'd lock myself in the bathroom, go to the back yard or lock myself in my room. I tried to, to stop hearing the fights, the arguments they had. (Carlos, 17 years old)

The narratives show that escape strategies and social support can be complementary, where sharing with peers is a common element. Three participants go out in search of their friends' company in activities aimed at temporarily distracting each other from the violence that exists in their homes and to receive emotional support.

(Is there anything that you do that helps you feel better?) [...] And... and I go out... or I don't know, like to play ball, like, to distract myself and so let go and... not, not think about that. (Héctor, 14 years old)

It should also be mentioned that, for avoidance behaviors, chronological age does not seem to be a determining factor. However, the temporality associated with age does emerge as relevant in the narrative of three adolescents. They create a distancing mechanism for past periods of their biography. For example, 13- and 17-year-old adolescents report that they used avoidance behaviors in the past, when they were younger. They indicate that, now that they are older, they respond mainly with intervention.

Before, I felt anger and sadness and I would go lock myself in the bathroom. (And now?) I separate them, I try to separate them, like this. (Daniela, 13 years old)

\section{Denial}

This strategy refers to the tendency to suppress the existence of acts of violence, by way of emotionally distancing oneself from its consequent negative effects. It was observed in only one case, the 12-year-old participant, who denies growing up with IPV episodes but gives an account of their occurrence when asked direct questions about these events:

(And how do you deal with these kinds of situations?) Letting it go. (Fabián, 12 years old).

It should be noted that the narrative of this participant shows difficulties integrating memories of IPV experiences. In effect, he expresses himself through succinct descriptions and abrupt answers. However, at the end of the interview, the adolescent acknowledged the existence of IPV episodes.

(How do you think you could change things?) Uh, getting my family to forgive each other [...] (What do they have to forgive each other?) When they fight. (Fabián, 12 years old)

\section{Discussion}

The purpose of this research was to understand, from the perspective of adolescents, the coping strategies used when facing IPV events between parents and/or caregivers. The results indicate that the adolescents face not only the specific episodes of IPV but also the consequences and family dynamics that accompany this type of violence. The narratives of the adolescents reveal seven coping strategies: intervention, social support seeking, protective role, positive resignification, hypervigilance, escape-avoidance, and denial. These are consistent with what is reported by other qualitative studies with adolescents who have grown up in homes with IPV (Åkerlund \& Sandberg, 2017; Aymer, 2008; Benavides, 2012; Goldblatt, 2003; Hague et al, 2002; Hines, 2015; Katz, 2016; Øverlien \& Hydén, 2009). These coping strategies account for the agency of adolescents to deal with situations of violence in their families (Callaghan et al., 2015; Øverlien \& Hydén, 2009) and proactively seeking solutions to stop said violence, protect others, and/or attenuate their negative feelings through distancing mechanisms. It is important to note that adolescents' agency is negotiated daily within their family and social contexts (Abebe, 2019), and therefore is socially and relationally produced, rather than a quality of a child or adolescent (Spyrou, 2018). In this sense, adolescent agency to respond to violence should be seen as contextual and relational responses, not as an innate capability.

The adolescents in our study assume different roles with different degrees and forms of involvement in IPV. Based on the conceptualization of the coping spectrum defined by Ravi and Casolaro (2018), ranging from integrating IPV to distancing from it, most of the coping strategies found in this study refer to the integration of violence, corresponding to problem-focused coping strategies (Lazarus \& Folkman, 1984). The coping strategies of social support seeking, intervention, protective role, positive resignification, and hypervigilance involve acknowledging the IPV and modifying behavior to cope with it, either by seeking help, taking action during the episodes, adopting a new caregiver role in the family system, taking action regarding the consequences, transforming this type of violence into learning and/or developing a state of constant alert that seeks to prevent violence. 
However, these results only account for coping strategies that involve the integration of violence into their daily lives by taking different actions, unlike what is proposed by Ravi and Casolaro (2018), who also account for strategies that minimize or normalize IPV, which were not found in this study.

Intervention in IPV episodes is one of the most direct strategies for stopping this type of violence. According to the literature, participants in this study recognize the risk posed by IPV and therefore intervene verbally and/or physically both during and after IPV episodes (Noble-Carr et al., 2020; Øverlien \& Hydén, 2009; Ravi \& Casolaro, 2018). In this study, such strategies were primarily nonviolent interventions, such as parent counseling, and only one male adolescent reported intervening at one time in a direct, violent manner by pushing the father against a wall. In contrast, two adolescent females reported no intervention due to fear of being harmed by the abuser if they became involved in the IPV episode. This is consistent with what has been reported in other studies about how the dynamics of control within families with IPV can result in adolescents feeling unable to control their own lives (Izaguirre \& Calvete, 2015). Thus, in the context of IPV, action becomes a possible risk to integrity (Øverlien \& Hydén, 2009) and it would be dangerous and irresponsible to assess problem-centered strategies as the best option for children living in families with violence (Miranda et al., 2021c). Therefore, the findings of this study help to challenge the notion that coping strategies can be classified as good or bad, or healthy or unhealthy, since growing up in the midst of violence can be a borderline survival experience in which adolescents seek various ways to adapt. In his last work, Lazarus (2006) pointed out that several studies have claimed that problem-focused coping is superior to emotion-focused coping regarding the generation of positive adaptational outcomes; however, the author highlights that other studies have reported the opposite findings, and most of the former studies have not considered crucial participant aspects, such as their situational and life context and their personal appraisals of what could, realistically, be done. In this regard, after decades of research treating problem-focused and emotion-focused coping as two independent approaches -separate and competing-, a crucial challenge has been raised to move forward to a clearer understanding of both coping functions complementing each other in most stress situations (Lazarus, 2006).

At the other end of the coping continuum proposed by Ravi and Casolaro (2018) there are strategies that seek to distance themselves consciously or subconsciously from the experience of IPV, either mentally or physically. This part of the continuum may include escape, avoidance and denial strategies that seek to elude IPV episodes or its consequences and are forms of emotion-focused coping strategies (Lazarus \& Folkman, 1984). The literature understands these strategies as a possible loss of control and agency (Hines, 2015), to the extent that adolescents perceive that they do not have sufficient competencies to deal with violence at home and/or to the extent that there is a lack of understanding of what is happening (Howell et al., 2016; Ravi \& Casolaro, 2018). With respect to the latter, the results obtained in this work provide new knowledge, namely that most of the adolescents in this research do develop a comprehensive view of their experience of IPV. However, the discomfort, confusion and pain that arise as a result of a traumatic experience such as IPV can be very difficult to manage (Noble-Carr et al., 2020) and in view of this, strategies such as escape, avoidance or denial can be deployed.

Another important aspect of our results shows that there could be a change in what IPV coping strategies are used as the adolescents grow up. Some participants report having previously used the escape-avoidance strategy, now using the intervention more frequently, having matured. Older participants in this study also reported using positive resignification to understand and use this experience in their lives in a positive way. This could be related to the coping with ambivalence literature (Van Harreveld et al., 2009), which states that ambivalent attitudes are unpleasant and different coping strategies are used to deal with these feelings. Emotion-focused coping strategies could be used to feel better without dealing with the problem, and problem-focused coping strategies could be used to change ambivalent attitudes to reduce discomfort. Assessing IPV may create conflict for children and, as they grow older, their views on violence and their parents may be more defined, directly impacting which coping strategy they will choose. On the other hand, findings on young people's meanings of IPV experiences reveal that the occurrence of psychological IPV led to ambiguity and confusion, while extreme, physical IPV is readily recognized as IPV, and this was useful to facilitate disclosure, discussion, and help-seeking (Naughton et al., 2019). It should be noted that, in our study, IPV was repeated or chronic in the adolescents' daily lives, with some mothers even reporting IPV during pregnancy, and all adolescents having suffered other victimizations within their lifespan. We recommend exploring this phenomenon further in future research, understanding coping strategies as dynamic forms of responding to violence, influenced by the context, individual and family characteristics (e.g., the presence of siblings) (Åkerlund, 2017; Arai et al., 2021; Hines, 2015). We also recommend exploring the influence of meanings related to IPV (Miranda et al., 2021b) and the co-occurrence of other victimizations (Miranda et al., 2021a). Finally, more research is needed to understand the influence of cultural characteristics (e.g., the cultural dimension of individualism-collectivism) on coping strategies in the field of IPV.

The findings of the study should be analyzed considering its limitations. Firstly, the characteristics of the 
semi-structured interview should consider that the amount of information collected depends on the skill of the interviewers. Due to this, this study provided interview management training to the program professionals administering the interviews. Secondly, the homogeneity of the sample must be recognized: the adolescents of this study were characterized by having had repeated or chronic IPV experiences during their lives, were all participating in protection programs and resided in urban areas. Future studies with larger and more diverse samples continues to be a challenge for clinical research. Our study contributes to the literature on youth who have experienced IPV between their parents by exploring the coping strategies of a group of adolescents who have experienced repeated/chronic IPV at home. Our results distinguish various ways in which adolescents acknowledge and respond to violence, and how the various ways of responding to violence may change with age. More generally, they contribute to the scarce research on this type of violence in Latin America and, especially, in Chile.

Regarding the implications of this study for practice, it reinforces the idea that both women and their offspring are victims of IPV (Artz et al., 2014; Holden, 2003). Consequently, children who have grown up in the context of IPV should be considered for preventive and assistance interventions that address this type of violence. The current global context marked by the COVID-19 pandemic emphasizes the importance of ensuring care and response services to IPV, as recent data indicate that the health emergency further aggravates this problem (UN Women, 2020) and victimization against children and adolescents could increase (Pereda \& Díaz-Faes, 2020). In the year 2020, the Chilean government reported 43 femicides and 151 frustrated femicides (Ministry of Women and Gender Equality, 2020), the highest number in the last eight years. Virus prevention and mitigation measures could reinforce the isolation of victims inside their homes and aid services could become overloaded. In the current context, it is urgent to confront IPV as another pandemic that cannot and must not remain in the shadows (UN Women, 2020). On the other hand, it is also important in clinical settings to consider adolescents who have grown up in households with IPV as people with agency capacity, who respond in various ways to IPV to survive their realities. Therefore, we invite those working in clinical settings with youth who have grown up in IPV homes to validate and consider the role that adolescents play in these contexts. There is a tendency among clinicians to see young people affected by IPV as "damaged" and lacking agency. It is important that practitioners give young people the space to articulate the many (and sometimes innovative) ways in which they respond to IPV and incorporate the recognition of this into treatment plans. Finally, the present findings call for a more integrative and comprehensive approach on youths coping with IPV, and for more collaboration between different research fields in different countries, as well as various services for youths and adults who have been victims of violence. Our study joins the efforts of researchers and practitioners working in the field of victimization, hoping to shed light on how to manage the complex phenomenon of victimization and move together toward more collaborative and kinder human relationships to face a challenging world, in this generation and the next.

Funding This study was funded by: Proyecto U-Inicia UI19/16- "Violencia de Género en la Pareja y Problemas de Salud Mental en Niñas, Niños y Adolescentes", Vicerrectoría de Investigación y Desarrollo, Universidad de Chile; and Programa de Estímulo a la Excelencia Institucional (PEEI), Facultad de Ciencias Sociales, Universidad de Chile via the fund Concurso de Fortalecimiento de Productividad y Continuidad en Investigación (FPCI) 2019-II, Universidad de Chile. MAC received funding from ANID/PFCHA/DOCTORADO NACIONAL/2019-21190859 and from ANID - Millennium Science Initiative Program - NCS17_035.

\section{Declarations}

Conflict of Interest None.

\section{References}

Abebe, T. (2019). Reconceptualising children's agency as continuum and interdependence. Social Sciences, 8(3), 81. https://doi.org/ $10.3390 /$ socsci8030081

Åkerlund, N. (2017). Caring or vulnerable children? Sibling relationships when exposed to intimate partner violence. Children \& Society, 31(6), 475-485. https://doi.org/10.1111/chso.12215

Åkerlund, N., \& Sandberg, L. J. (2017). Children and violence interactions: Exploring intimate partner violence and children's experiences of responses. Child Abuse Review, 26(1), 51-62. https://doi. org/10.1002/car.2438

Arai, L., Heawood, A., Feder, G., Howarth, E., MacMillan, H., Moore, T. H., \& Gregory, A. (2021). Hope, agency, and the lived experience of violence: A qualitative systematic review of children's perspectives on domestic violence and abuse. Trauma, Violence, \& Abuse, 22(3), 427-438. https://doi.org/10.1177/1524838019 849582

Artz, S., Jackson, M., Rossieter, K., Nijdam-Jones, A., Géczy, I., \& Porteus, S. (2014). A comprehensive review of the literature on the impact of exposure to intimate partner violence for children and youth. International Journal of Child, Youth and FamilyStudies, 5(4), 493-587.

Aymer, S. R. (2008). Adolescent males' coping responses to domestic violence: A qualitative study. Children and Youth Services Review, 30, 654-664. https://doi.org/10.1016/j.childyouth.2008.01.011

Benavides, L. E. (2012). A phenomenological study of spirituality as a protective factor for adolescents exposed to domestic violence. Journal of Social Service Research, 38(2), 165-174. https://doi. org/10.1080/01488376.2011.615274

Callaghan, J. E. M., Alexander, J. H., Sixsmith, J., \& Fellin, L. C. (2015). Beyond witnessing children's experiences of coercive control in domestic violence and abuse. Journal of Interpersonal Violence, 1-31,. https://doi.org/10.1177/0886260515618946 
Chanmugam, A. (2015). Young adolescents' situational coping during adult intimate partner violence. Child \& Youth Services, 36(2), 98-123. https://doi.org/10.1080/0145935X.2014.990627

Consejo Nacional de la Infancia. (2018). Análisis multivariable de estudio polivictimización en niños, niñas y adolescentes [Multivariate analysis of polyvictimization study in children and adolescents]. http://www.creciendoconderechos.gob.cl/docs/Informe_Final_ polivictimizacion.pdf

DeBoard-Lucas, R. L., \& Grych, J. H. (2011). Children's perceptions of intimate partner violence: Causes, consequences, and coping. Journal of Family Violence, 26, 343-354. https://doi.org/10.1007/ s10896-011-9368-2

Devries, K., Merrill, K. G., Knight, L., Bott, S., Guedes, A., ButronRiveros, B., ... \& Abrahams, N. (2019). Violence against children in Latin America and the Caribbean: What do available data reveal about prevalence and perpetrators? Revista Panamericana de Salud Pública, 43. https://doi.org/10.26633/RPSP.2019.66

Eriksson, M., \& Näsman, E. (2012). Interviews with children exposed to violence. Children and Society, 26, 63-73. https://doi.org/10. 1111/j.1099-0860.2010.00322.x

Evans, S., Davies, C., \& Dilillo, D. (2008). Exposure to domestic violence: A Meta-analysis of child and adolescent outcomes. Aggression and Violent Behavior, 13, 131-140. https://doi.org/ 10.1016/j.avb.2008.02.005

Gaínza, A. (2006). La entrevista en profundidad individual [The individual in-depth interview]. In M. Canales (Ed.), Metodologías de investigación social. Introducción a los oficios [Social research methodologies. Introduction to the trades] (pp. 219264). LOM Ediciones.

Goldblatt, H. (2003). Strategies of coping among adolescents experiencing interparental violence. Journal of Interpersonal Violence, 18(2), 532-552. https://doi.org/10.1177/0886260503 251071

Hague, G., Mullender, A., Kelly, L., Imam, U., \& Malos, E. (2002). How do children understand and cope with domestic violence? Practice, 14(1), 17-26. https://doi.org/10.1080/0950315020 8414289

Heise L. y García-Moreno, C. (2002). Violence by intimate partners. In E.G. Krug, L.L. Dahlberg, J.A. Mercy, A.B. Zwi \& R. Lozano (Dirs.), World report on violence and health (pp. 87-121). World Health Organization.

Hines, L. (2015). Children's coping with family violence: Policy and service recommendations. Child and Adolescent Social Work Journal, 32, 109-119. https://doi.org/10.1007/s10560-014-0333-9

Holden, G. W. (2003). Children exposed to domestic violence and child abuse: Terminology and taxonomy. Clinical Child and Family Psychology Review, 6(3), 151-159. https://doi.org/10.1023/A: 1024906315255

Holt, S., Buckley, H., \& Whelan, S. (2008). The impact of exposure to domestic violence on children and young people: A review of the literature. Child Abuse \& Neglect, 32(8), 797-810. 1016/j. chiabu.2008.02.004

Howell, K. H., Barnes, S. E., Miller, L. E., \& Graham-Bermann, S. A. (2016). Developmental variations in the impact of intimate partner violence exposure during childhood. Journal of Injury and Violence Research, 8(1), 43. https://doi.org/10.5249/jivr.v8i1.663

Imbusch, P., Misse, M., \& Carrión, F. (2011). Violence research in Latin America and the Caribbean: A literature review. International Journal of Conflict and Violence, 5(1), 87-154. https://doi. org/10.4119/ijcv-2851

Izaguirre, A., \& Calvete, E. (2015). Children who are exposed to intimate partner violence: Interviewing mothers to understand its impact on children. Child Abuse \& Neglect, 48, 58-67. https:// doi.org/10.1016/j.chiabu.2015.05.002

Katz, E. (2016). Beyond the physical incident model: How children living with domestic violence are harmed by and resist regimes of coercive control. Child Abuse Review, 25(1), 46-59. https:// doi.org/10.1002/car.2422

Kimball, E. (2016). Edleson revisited: Reviewing children's witnessing of domestic violence 15 years later. Journal of Family Violence, 31(5), 625-637. https://doi.org/10.1007/s10896-015-9786-7

Kitzmann, K., Gaylord, N., Holt, A., \& Kenny, E. (2003). Child witnesses to domestic violence: A meta-analytic review. Journal of Consulting and Clinical Psychology, 71(2), 339-352. https://doi. org/10.1037/0022006X.71.2.339

Korstjens, I., \& Moser, A. (2018) Series: Practical guidance to qualitative research. Part 4: Trustworthiness and publishing. European Journal of General Practice, 24(1), 120-124

Lazarus, R. S. (2006). Emotions and interpersonal relationships: Toward a person-centered conceptualization of emotions and coping. Journal of Personality, 74(1), 9-46. https://doi.org/10. 1111/j.1467-6494.2005.00368.x

Lazarus, R. S. (1999). Stress and emotion: A new synthesis. Springer.

Lazarus, R. S., \& Folkman, S. (1984). Stress, appraisal, and coping. Springer.

Ministry of Women and Gender Equality (2020). Femicidios [Feminicides]. https://www.sernameg.gob.cl/wp-content/uploads/2021/ 01/FEMICIDIOS-al-31-de-diciembre-de-2020.pdf.

Miranda, J. K., \& Corovic, J. (2019). Violencia de género en la pareja: aproximación comprensiva a las vivencias de niños y niñas [Exposure to intimate partner violence: Comprehensive approach to children's experiences]. Universitas Psychologica, 18(3), 1-14. https://doi.org/10.11144/Javeriana.upsy18-3.vgpa

Miranda, J. K., Crockett, M. A., \& Vera-Pavez, J. I. (2021a). The co-occurrence of intimate partner violence exposure with other victimizations: a nationally representative survey of Chilean adolescents. Child Abuse \& Neglect, 117. https://doi.org/10.1016/j. chiabu.2021.105046

Miranda, J. K., Domedel, C., Crockett, M. A., Azócar, E., \& Thatcher, K. (2021b). Growing up in the context of intimate partner violence: Experiences and meanings for adolescents in Chile. Child Abuse \& Neglect, 120. https://doi.org/10.1016/j.chiabu.2021. 105220

Miranda, J. K., León, C., \& Crockett, M. A. (2021c). A qualitative account of children's perspectives and responses to intimate partner violence in Chile. Journal of Interpersonal Violence, $36(23-$ 24), NP12756-NP12782. https://doi.org/10.1177/0886260520 903132

Miranda, J. K., Rojas, C., Crockett, M. A., \& Azócar, E. (2021d). Child perspectives on growing up with gender-based intimate partner violence at home. Anales de Psicología, 37(1), 10-20. https://doi. org/10.6018/analesps.429651

Morris, A., Hegarty, K., \& Humphreys, C. (2012). Ethical and safe: Research with children about domestic violence. Research Ethics, 8(2), 125-139. https://doi.org/10.1177/1747016112445420

Morse, J., Barret, M., Mayan, M., Olson, K., \& Spiers, J. (2002). Verification strategies for establishing reliability and validity in qualitative research. International Journal of Qualitative Methods, $1(2), 13-22$.

Naughton, C. M., O’Donnell, A. T., \& Muldoon, O. T. (2019). Young people's constructions of their experiences of parental domestic violence: A discursive analysis. Journal of Family Violence, 34, 345-355. https://doi.org/10.1007/s10896-018-0013-1

Noble-Carr, D., Moore, T., \& McArthur, M. (2020). Children's experiences and needs in relation to domestic and family violence: Findings from a meta-synthesis. Child \& Family Social Work, 25(1), 182-191. https://doi.org/10.1111/cfs.12645

Øverlien, C., \& Hydén, M. (2009). Children's actions when experiencing domestic violence. Childhood, 16(4), 479-496. https://doi.org/ 10.1177/0907568209343757

Pereda, N., \& Díaz-Faes, D. A. (2020). Family violence against children in the wake of COVID-19 pandemic: A review of current 
perspectives and risk factors. Child and Adolescent Psychiatry and Mental Health, 14(1), 1-7. https://doi.org/10.1186/ s13034-020-00347-1

Pinto-Cortez, C., Pereda, N., \& Álvarez-Lister, M. S. (2018). Child victimization and poly-victimization in a community sample of adolescents in northern Chile. Journal of Aggression, Maltreatment \& Trauma, 27(9), 983-1002. https://doi.org/10.1080/10926 771.2017 .1410748

Ravi, K. E., \& Casolaro, T. E. (2018). Children's exposure to intimate partner violence: A qualitative interpretive meta-synthesis. Child and Adolescent Social Work Journal, 35(3), 283-295. https://doi. org/10.1007/s10560-017-0525-1

Riessman, C. K. (2002). Narrative analysis. In M. Huberman \& M. Miles (Eds.), The qualitative Researcher's companion (pp. 217270). Sage Publications.

Spyrou, S. (2018). What kind of agency for children? In Disclosing childhoods (pp. 117-156). Palgrave Macmillan.

Subsecretaria de Prevención del Delito. (2013). Encuesta nacional de victimización por violencia intrafamiliar y delitos sexuales [National victimization survey on domestic violence and sexual offenses]. http://www.seguridadpublica.gov.cl/filesapp/Presentaci on\%20VIF_adimark_final.pdf
United Nations Entity for Gender Equality and the Empowerment of Women (UN Women) (2020). COVID-19 and ending violence against women and girls. https://www.unwomen.org/en/digitallibrary/publications/2020/04/issue-brief-covid-19-and-endingviolence-against-women-and-girls

Van Harreveld, F., Van der Pligt, J., \& de Liver, Y. N. (2009). The agony of ambivalence and ways to resolve it: Introducing the MAID model. Personality and Social Psychology Review, 13(1), 45-61. https://doi.org/10.1177/1088868308324518

Vu, N., Jouriles, E., McDonald, R., \& Rosenfield, D. (2016). Children's exposure to intimate partner violence: A meta-analysis of longitudinal associations with child adjustment problems. Clinical Psychology Review, 46, 25-33. https://doi.org/10.1016/j.cpr. 2016.04.003

Wolfe, D. A., Crooks, C. V., Lee, V., Mcintyre-Smith, A., \& Jaffe, P. G. (2003). The effects of children's exposure to domestic violence: A meta-analysis and critique. Clinical Child and Family Psychology Review, 6(3), 171-187. https://doi.org/10.1023/A:1024910416164

Publisher's Note Springer Nature remains neutral with regard to jurisdictional claims in published maps and institutional affiliations. 